\title{
Postdigital Living in the Age of Covid-19: Unsettling What We See as Possible
}

\author{
Neil Selwyn ${ }^{1} \cdot$ Petar Jandrić ${ }^{2,3}$ \\ Published online: 9 July 2020 \\ (C) Springer Nature Switzerland AG 2020
}

Keywords Covid-19 · Postdigital living • Democracy • Artificial Intelligence · EdTech • Dataification · Inequality · Labour · Political economy · Decision making · Educational futures $\cdot$ New normal $\cdot$ Conversation

\section{Introduction}

Neil Selwyn is a social scientist who has spent the past 25 years writing about digital technology and education from a variety of perspectives. Starting his career in Cardiff University School of Social Sciences (UK), Neil has also worked at the UCL Knowledge Lab (UK) and Monash University Faculty of Education (Australia). A common theme throughout Neil's work has been the ambition to look beyond the usual teaching and learning concerns of 'EdTech' research, and instead explore the broader ways in which digital technology and education come together. This has led Neil's work to explore issues ranging from the formation of national educational computing policies, through to the ongoing persistence of digital inequalities in local communities.

Neil is currently working on research projects examining the datafication of schools, artificial intelligence (AI) technologies and the automation of classrooms, the implementation of facial recognition in everyday life, and the changing nature of teachers' digital labour. His recent books include the third edition of Education and Technology: Key Issues \& Debates (Selwyn 2021), Should Robots Replace Teachers? (Selwyn 2019), and What is Digital Sociology? (Selwyn 2019).

Neil Selwyn

neil.selwyn@monash.edu

Petar Jandrić

pjandric@tvz.hr

1 Monash University, Melbourne, Australia

2 Zagreb University of Applied Sciences, Zagreb, Croatia

3 University of Wolverhampton, Wolverhampton, UK 


\section{About the Conversation}

In May 2020, Petar Jandrić emailed Neil Selwyn with an idea for this conversation. Neil wanted to converse in writing, so the conversation was conducted through several email exchanges between May and July 2020.

\section{Postdigital Living and Its Inequalities}

Petar Jandrić (PJ): In 2013 you argued for a need for developing global perspectives on technology and education. Following 'Colin Hay's distinction between the notion of globalisation as discourse and globalisation as process (see Hay and Rosamond 2002)' (Selwyn 2013: 8), you asserted that most academic discussions in the field, including yours, refer to globalisation as discourse. In early 2020, after almost two billion of worldwide teachers and learners shifted online in few short weeks due to the Covid-19 pandemic (Miks and McIlwaine 2020), we have a unique historical opportunity to examine globalisation of technology and education as process. These days, theories that we have been developing for decades are facing the largest global reality check (so far) in our lifetimes.

Please reflect on pre-Covid-19 theories of global perspectives on technology and education in the context of current events. Which aspects of (your) pre-Covid-19 critique have remained the more or less unchanged? Which aspects have risen into prominence, and which require significant updates?

Neil Selwyn (NS): While I was convinced at the time that it made some important points, that 2013 book is definitely one of my lowest-selling and least-cited books of all time. As I recall, my main intention when putting that book together was to push back against the idea that EdTech is a 'one-size-fits-all' globalising phenomenon. This might seem an obvious argument to make in 2020 , but I was writing at a time when people were still in thrall to Bill Gates' mantra that 'content is king' $(1996)^{1}-$ i.e. the belief that digital technology was all about content and connectivity rather than context. The hype around the global take-up of Facebook and other social media was getting ridiculous. This was a time when we had supposedly witnessed a succession of 'Twitter revolutions' across the Arab world. This was just before the hubris of Facebook's 'Free Basics' incursion into India (Bhatia 2016). Matters of local context, culture, history and geopolitics were all presumed irrelevant in the face of this Western (perhaps even Californian) digital revolution.

As is usually the case, such assumptions had trickled down into EdTech circles, and clearly needed to be examined and problematised. If I remember correctly, the specific event that tipped me over the edge was seeing the Samsung container classrooms being airlifted in South African villages (see Samsung 2013). This was literally a Westernstyle classroom for 20 kids, kitted out with solar-powered Samsung notebook devices, webcams and a 50 inch whiteboard - all crammed into a 40 foot shipping container. For some reason I did not dwell too much on neo-colonialization arguments in the book, but the connotations were plain to see.

\footnotetext{
${ }^{1}$ The essay, originally published on the Microsoft website, has since been taken down and the original is now available only at Internet WayBack Machine (Gates 1996).
} 
PJ: So how did the book come about?

NS: The book came together quickly. I already had some things written about One Laptop Per Child - a telling example of 'tech-bro' hubris that was still a subject of unconditional love from the open-source fan-boys and Media Lab apologists ... despite the fact that it was clearly tone-deaf to matters of local culture and regional politics. I also had something written on the cultural precedents of physical robotics in Japan, and a piece that Phil Brown and I had written about the worldwide turn to EdTech policymaking - policies like the extraordinary series of Singaporean 'Masterplans for ICT' (Selwyn and Brown 2000). Armed with examples like this, I wanted to explore the localised flavours and regionalised iterations of education and technology around the world. I was fascinated by the way that EdTech was talked about and enacted within ICT4D (Information and Communications Technologies for Development) communities - an area of work that still does not cross-over as much as it should into discussions of EdTech in the global North. I was interested what Islamic or Confucian EdTech might look like. I was interested in how Nepal had developed its national ICT agenda as compared to Norway's agenda. All these examples added up to suggest that the discourse of 'globalised' EdTech was not being reflected on the ground.

I have not given it much thought, but I'd imagine that the same might well be true for the ways in which Covid-19-era digital education has been playing out around the world. It feels a little odd to be talking about globalisation in 2020. We are increasingly being told that globalisation is dead and that populist nationalism is on the rise. Of course, the pandemic has seen the usual 'Big Tech' transnational corporations look for ways to extend their reach. It has also seen the usual supra-national suspects such as the OECD and World Bank push forward their agendas for establishing a digitally-driven 'new normal'. But looking at the ways in which different regions and countries coped with the first wave of school shutdowns, there have been marked local variations and straightforward differences that confound such discussion - even if we only focus on the experience of countries in the global North.

PJ: Indeed - as can easily be seen in this issue of Postdigital Science and Education, global responses to Covid-19 lockdowns are far from uniform. And these responses do not only depend on finances - they also reflect wider political choices of their communities.

NS: This can be seen in the initial take-up of Zoom, which was quickly rescinded in jurisdictions where attention was paid to issues around data privacy and system integrity, while taken up with gusto elsewhere where such concerns do not prevail. GDPR (General Data Protection Regulation) put paid to online practices within EU countries that blossomed in countries with no such legislation. Chinese authorities were enforcing all sorts of digital education governance through their leading platforms such as Lark and DingTalk. Thrown into this mix, of course, are the diverse experiences of countries in the global South. Remote schooling has taken all sorts of forms there from a resurgence in educational radio and television, through to preloaded mobile devices, text messaging, bundles of books and paper worksheets. As well as betweencountry differences, there have also been huge between-class differences. It is reported that perhaps up to $20 \%$ of US students were essentially 'missing in action' and making little or no contact with schools during the first lockdowns (Sawchuk and Samuels 2020). This was a global pandemic, but the idea of 'everyone all being in this together' did not apply to our collective experiences of digital technology and education. 
In fact, one of the aims of Education in a Digital World (Selwyn 2013) was to push the reader into reflecting on how EdTech differs in local and hyper-local contexts. One thing that the pandemic has pushed to the fore is the differentiated nature of how remote schooling was encountered and experienced within local communities, within individual schools, even within the same class of students. We've seen teachers in Australia (and I'm sure this has been the case in North America and Europe) suddenly have to run two or three different strands of remote schooling provision for their classes catering for the 5G households, the dial-up households, and those with little or no connectivity at all ('home-schooling six children with just one phone' as a BBC News report (2020) put it). We've seen schools having to mix-and-match what they have been doing, using a hodgepodge of technology, and also having to resort to packs of paper worksheets and books. There has not been one homogenous remote schooling experience within any individual school, let alone across a whole city. So to talk of EdTech as a globalised process in 2020 makes no sense at all. If anything, EdTech in 2020 has been a worldwide mess.

PJ: And it is our job to make at least some sense of that mess! Soon after settling into our lockdown working-from-home routines, we rediscovered some oft-neglected and politically side-lined aspects of online education. Those working from nice large houses have it much better than those working from tiny apartments. Childless couples and couples with grown-up children have it much better than those who home-school their children on top of working full-time jobs. Tenured academics have it much better than adjuncts. Instead of postdigital learning, we now need to speak of a wider concept of postdigital living (Lacković 2020). Postdigital living cannot be thought of without traditional concepts and themes of critical pedagogy such as class, property ownership, social provisions, race, and others, yet these concepts and themes are now also undergoing significant transformations. In Schools and Schooling in the Digital Age: A critical analysis Selwyn (2011b), and also elsewhere, you wrote about many of these themes. What are the main lessons from worldwide lockdown for your pre-pandemic research of the role(s) that digital technologies play in people's everyday lives in the context of postdigital living?

NS: Well, I hope that one of the big lessons that we take from the first wave lockdowns is that digital inequalities are as entrenched and important as issue as ever. A lot of my previous answer relates to key issues of digital inequality along the familiar lines of class, race, geography, dis/abilty and gender. I have paid close attention to issues of digital inequality since the late 1990s, and it has always been difficult to get people in education to take the matter seriously. Hopefully, this pandemic has foregrounded the issue in the minds of school leaders, policymakers, and quite a lot of academics as well. We are not 'all online now' as people were fond of responding before Covid-19 when you tried to raise the question of digital inequalities. Prior to the pandemic there was plenty of evidence confirm the so-called 'homework gap' - i.e. that nearly 20 percent of US teens report being unable to complete school work at home due to lack of devices and/or connectivity (Anderson and Perrin 2018). Gaps like these have blighted remote schooling during the lockdowns - especially for the low-income, black households where these issues are most prevalent.

For me, the pandemic has shone light on a range of disparities, divides and disadvantages associated with digital education. For example, we have seen how 
responsibility for dealing with the logistics (and emotional fallout) of remote schooling often falls disproportionately to mothers rather than fathers - highlighting the need to locate our understandings of digital education within the gendered politics of domestic labour. Similarly, remote school clearly did not work for many students with what is still referred to in education as 'special needs', and indeed for students for whom school is an invaluable source of support and respite. So, in all these ways it is fair to conclude that 'postdigital living' is just as unfair and compromised as any other form of living.

PJ: Indeed! I would argue, further, that the pandemic has not merely shone light on a range of disparities, divides and disadvantages associated with digital education together with emphasizing old inequalities, it has also introduced new ones.

NS: As you imply in your question, what the pandemic also did was focus our attention on the home as a compromised site of digital education. For sure, people have experienced all sorts of unexpected movements of creativity, spontaneity, and joyful home learning and home teaching. But, even the most well-resourced middle-class households have found all sorts of stresses, strains and glitches coming to the fore. For example, two white collar professionals working in a house with two online students (and nowhere else for anyone to escape to) raises all sorts of tensions, stresses and breakdowns that people from comfortable backgrounds are not necessarily accustomed. Even the most well-resourced postdigital household is a place of battles over devices and bandwidth, or awkward negotiations over not encroaching on important synchronous video meetings.

As Heather De-Quincey put it, many of us have been 'living at work' rather than 'working from home'. ${ }^{2}$ Many of us have experienced the phenomenon of 'Zoom fatigue', and the discombobulated feeling of spending all day online (supposedly working) and then all evening online (supposedly relaxing). Unfamiliar routines and rhythms where weekdays morph into weekends has made for an unsettling existence ... within which students and teachers have been attempting to enact some form of schooling. Of course, all this pales into insignificance when you consider the terrors of living/working/being trapped in a household which is a site of domestic abuse, or similarly chaotic for many other reasons. The lockdowns have starkly illustrated the limitations of presuming digital education to be an immaterial process. Digital education always takes place somewhere (more accurately, in multiple somewheres). When that somewhere is a household then the institutional boundaries of the family need to be factored much more prominently into our discussions over what digital learning is.

\section{Reaching Beyond 'What Works and Why?'}

PJ: In a mission statement article published by editors of Postdigital Science and Education few months before journal's launch (Jandrić et al. 2018), we outlined our initial take on the concept of the postdigital. We emphasized its roots in the arts, architecture, Silicon Valley culture, humanities, social sciences, philosophy, and other fields. We drew from various tradition including critical posthumanism, networked learning, critical pedagogy, and many others, and we wrote that '[t]he postdigital is hard to define; messy; unpredictable; digital and analog; technological and non-

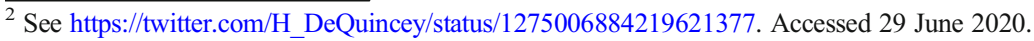


technological; biological and informational. The postdigital is both a rupture in our existing theories and their continuation.' (895).

Please describe your take on the concept of the postdigital. What is its relevance for your own work?

NS: I was vaguely aware of the idea of 'postdigital' from knocking around art galleries in the 2000s, so was interested to see people like yourself and Siân Bayne begin using the term with regards to educational technology and digital education. To be honest I have not paid close attention to where those education-related discussions have been going - primarily because my work over the past 5 years or so has seemed to focus more on the politics of school-related technology use, rather than tertiary and online education. From what I see, most of the postdigital education discussions tend to be focused primarily on online teaching and e-learning? Maybe I'm mistaken in that ... as I say, I have not been paying as close attention as I should! Actually, I should confess to not paying super-close attention to the 'education studies' literature in general. I try to read everything but the education literature, as this tends to where the most interesting ideas, debates and discussions about technology (and often education) take place. For my current work on AI, facial recognition and digital labour, nearly all of the interesting stuff is to be found well beyond education, so I am a little out of the loop when it comes to the latest trends in education journals and conferences.

PJ: I completely agree! Many postdigital discussions indeed focus to online teaching and learning, yet my own take at the postdigital perspective, and the way we develop this perspective in Postdigital Science and Education, is much broader. The journal is about postdigital science in the continental European meaning of the phrase, denoting inquiry or research in general (rather than natural sciences), and with a strong accent to arts. We are obviously interested in education, but we do tend to avoid sameold reports about using this or that technology in this or that educational context (see Jandrić 2019; Jandrić and Kuzmanić 2020). So our postdigital project, as I see it, is an attempt to inquire issues beyond traditional educational sciences while keeping education in the loop.

NS: I'm always happy to see further diversification of how technology and education is being talked about, and it is great that you have got people drawing on ideas well outside the usual EdTech comfort zone of learning theories and teacher practice. For me, the idea of 'postdigital' seems to chime with the approach that I have always tried to take - i.e. to approach the digital as deeply unspectacular, and also full of flaws, glitches, gaps, seams and artifices. So, from my reading of people like Dave Berry, I have always taken 'postdigital' to mean looking beyond apparent technological progress and novelty, and instead acknowledge our uneasy sense of ennui and disillusionment with contemporary technology-laden society. This reading of the term fits well with the recent societal 'techlash' that we are seeing in the West in light of the Snowden NSA revelations, the Cambridge Analytica scandal, and the pushback against 'cop tech' such as facial recognition. So, the term is a useful signpost that we have we have moved on from the initial rush of digital education, and we now need scholarship where attention is focused on what is happening 'after-the-digital' as Sy Taffel (2016) puts it.

PJ: Your examples refer to science and research, yet the concept of the postdigital, from its inception in early 2000s until today, is deeply inter-related with arts. More broadly, these days we are witnessing an increasing demand to somehow connect the two traditionally independent systems of inquiry characteristic for sciences and arts (see 
Jandric 2016). What is your take to the relationships between sciences and arts in postdigital research?

NS: Like I say, I've not really paid too much attention to the postdigital turn in terms of research per se. I'm not sure it fits the bill of 'postdigital', but I would note that the most interesting thinking and critique in some of my current areas of work are coming from collaboration between artists, activists and researchers. I have long admired the work of Trevor Paglan, for example. His recent work with Kate Crawford on 'ImageNet Roulette $^{3}$ was a great provocation with regards to exploring the politics of images in machine learning training sets. Similarly, Kate Crawford's collaboration with Vladan Joler in producing that vast visualisation of 'An Anatomy of an AI System'4 is a gamechanger in terms of interrogating familiar digital technologies from historical, material, ecological and planetary-scale perspectives. In comparison to these sorts of arts-based interventions, it is hard to think how education researchers can keep up.

PJ: Since we published our mission statement article, the concept of the postdigital has been criticized on various grounds. Paul Levinson writes: 'I do not disagree that we are in a postdigital age. I disagree that we are first entering it now' (Levinson 2019: 14). Andrew Feenberg similarly claims: "In reality, these terms "digital" and "postdigital" seem artificial. If the terms have something like the content I am ascribing them, then the postdigital preceded the digital and should be called the predigital instead' (Feenberg 2019: 9). Just few days ago, Ronald Barnett wrote:

An implication of the term is that we can get beyond the digital and put the digital behind us or, at least, move onto a higher level of being; but any such temptation must be eschewed. Even those who have no access to computers (often forgotten by those in higher education) are influenced by the Internet, if only in services, messages, cultural resources and information denied to them. We are all not postdigital but co-digital, whether we like it or not. (Hayes et al. 2020).

Few months ago you interviewed Siân Bayne at your podcast (Selwyn 2020) about postdigital education, and she expressed similar concerns.

Here I deliberately avoided positive critiques of the concept, which are just as plentiful as cautious and negative ones. Yet I do feel that many of these responses somehow aim at a wrong target. Looking at Barnett's above critique, for instance, why cannot we all be postdigital and co-digital at the same time? On the one hand, I am extremely thankful for all these critiques because they contribute to development of our collective understanding of relationships between humans and technologies. On the other hand, I cannot help but feel that this academic passion for endless clarification of concepts says more about human (in)ability to deal with complexity than about reality we are trying to understand and about academic games of prestige. And while it could be argued that it is best to avoid giving simple names to complex issues, we still need names - if for nothing else, then for practical purposes such as naming academic journals.

This brings about an academic Catch 22: Concepts cannot arrive into existence without names, yet names (digital education, postdigital education, Technology

\footnotetext{
${ }^{3}$ See https://www.excavating.ai/. Accessed 30 June 2020.

${ }^{4}$ See https://anatomyof.ai/. Accessed 30 June 2020.
} 
Enhanced Learning, networked learning...) are always contested. Everyone knows what is medicine, physics, history, and sociology, yet ed-tech community has not managed to define its own field for many decades. What, in your opinion, is the way forward from this conceptual and terminological mess characteristic for research into relationships between humans (learning) and technologies from its beginnings?

NS: I always think it is best not to take these things too seriously. I am always amused by the tribal nature of academia - especially within an applied area of study like 'education', which often feels to be much less than the sum of its parts. I am reminded of the cliché (which I've just learnt from Wikipedia (2020) is called 'Sayre's Law') that 'academic politics are so vicious precisely because the stakes are so small'. In that sense, publishing any sort of mission statement is going to attract hostility ... if you did not get any criticism then I'd be worried that you were doing it wrong!

Some of the comments you mention are interesting, and show how people will inevitably take the idea of 'postdigital' education in ways that conform to their preexisting positions and mindsets. I'm not sure I would look to Ron Barnett for a close reading of what the digital is, any more than he would look to me for a close reading of that the modern university is. But if the idea of 'postdigital' acts as a prompt for scholars like Ron to think more carefully about what they consider to be worth talking about when it comes to talking about the digital, then the term serves its purpose as a provocation. Even if you do not like the term, the notion of 'postdigital' acts as a reminder that there's something not quite right about the relentlessly apolitical ways in which 'digital' education is usually talked about.

PJ: Your argument echoes Jeremy Knox's recent editorial, 'Postdigital as (Re)Turn to the Political' (Knox 2019), and further reminds me of Sinclair and Hayes' reflection: 'When the prefix post(-) triggers us to recognise that there is something to talk about in the term that follows, with the word 'digital' it signals that we have not done with the digital and there are some material aspects of the digital that cannot be physically composted.' (Sinclair and Hayes 2019: 130) Great to see these concordances!

NS: People are always going to make the assumption that Barnett alludes to in his response - i.e. that 'postdigital' denotes moving onto a higher level of being. I guess I've taken my definition of 'postdigital' to simply mean 'moving beyond the digital hype'. Given my generally pessimistic outlook, my preferred flavour of 'postdigital' would be as a prompt to think about ways in which the digital has perhaps dragged human society backwards. On the other hand, I understand why others are more interested in more transformative transhuman questions. Perhaps, then, 'postdigital' can act as a temporary flag of convenience for people who want to ask more interesting questions about the digital that look beyond the usual 'What Works and Why?' perspectives that blight EdTech writing ... but also looking beyond the sociological concerns about inequalities, politics, disadvantage and power that the 'critical studies of EdTech' people (myself included) are interested in. People always assume that because I try to take a 'critical' approach to EdTech that I must be anti-technology. So I'm not surprised that people parse the notion of 'postdigital' in a literal manner. If 'postdigital' is that hopeless a term then I'm sure people will soon gravitate to other variations. EdTech is a constant churn of labels, movements and cliques.

As for your question regarding the contested 'names' that tend to arise in EdTech, I'm not so sure that there is that much stability and consensus elsewhere. People are always arguing in sociology whether something is 'proper sociology' or not, especially 
in terms of applied sociological work in education or health. I imagine the same is the case in medicine or architecture! So, I guess I am quite comfortable about the area within which my work is focused being a 'conceptual and terminological mess'. For me, education and technology is just a topic ... I'd hate to see it take on pretentions of being a field or discipline. And if it did, then I'd probably do all I can to position myself outside that field or discipline. I do not see the need for EdTech scholars to reinvent the wheel. In terms of concepts, ideas, theories and methods of inquiry, I would prefer to concentrate on encouraging people interested in exploring EdTech to think more carefully about bringing in a wider range of concepts, ideas, theories and methods of inquiry from elsewhere. What exactly is it about relationships between humans and technologies that you are especially interested in, and where are these questions being more fruitfully explored outside of education?

\section{Cultivating Good 'Habits' Around Artificial Intelligence}

PJ: These days, AI is considered as the hottest research frontier in many fields including education. In Should Robots Replace Teachers?: AI and the Future of Education you wrote:

Despite the obvious advantages to be gained from preparing for an increasingly automated future, education continues to be one of the least future-focused sectors there is. If anything, educators tend to take perverse professional pride in their capacity to deal with crises as they occur. Yet when it comes to AI and automation, resignedly waiting for the worst is likely to have ruinous results. (Selwyn 2019).

What should we do instead of resigned waiting? How should we start preparing for the future world of AI and automation?

NS: The vibe of that particular book is that the future of AI and education is not set in stone. Even the most advanced AI-driven technologies are in an early stage of development, and there is plenty of scope for educators and non-experts to start speaking up about what types of AI they want. If we allow ourselves a moment of hope, then perhaps educators should not be preparing for a pre-destined future of AI they can actively shape it. More so than ever, the current hyperbole around AI and education encapsulates the idea of digital technology being 'a solution in search of a problem'. So, at the very least, now is the time for educators (and others who care about education) to speak up about the real-world issues that they see as worth trying to address through this technology.

Here's a brief example for you. There has been a furore here in Melbourne prompted by a local start-up attempting to get its facial recognition product into schools. They have been trying to do this under the guise of a simple iPad 'system' that they claim is able to take the class register - i.e. mark kids off the rollcall automatically using facial recognition. They claim that this will save the average teacher a purported 2.5 hours of work a week. Since when has the roll call been a massive problem for teachers and schools that they have so far proved unable to solve? Since when has this been a 
problem that warrants the incursion of high pernicious 'cop tech' into classrooms with all the discriminatory, oppressive and damaging implications that we know facial recognition technology entails? Rather than have AI technologies foisted onto schools and universities in such wrong-headed and profit-hungry ways, it now falls to educators to push back and suggest alternate ways that this AI might be useful.

I do not want to come across as anti-AI. On the contrary, this is certainly impressive and fascinating technology - so let us work out ways of using it in impressive and fascinating ways. For the most part, AI developers have very limited experience of schools and universities - often merely their personal experiences of learning (and perhaps lecturing) along the path to working in computer science. On the other hand, whole communities of teachers and students have heaps of diverse different experiences. In the book I suggest that rather than using AI in education to do existing things in different ways, perhaps we could explore how to use AI to do things that have hitherto been unimaginable. There are some great examples of creative AI that might be really exciting to use in education - the areas of natural language generation and image generation have really interesting connotations. These are forms of AI that might be really productive to have in a classroom, but it is up to educators to set these agendas running, and also to shout loudly about the detrimental consequences of the more managerial, disciplinary forms of AI-driven technology that we seem to be getting.

PJ: AI and automation introduce and / or exacerbate many complex questions including but far from limited to surveillance, human rights, and others. Your book Should Robots Replace Teachers?: AI and the Future of Education (Selwyn 2019) begins and ends with quotes from John Dewey, so I cannot help but ask: What is the role of education at the intersections between AI, automation, and democracy?

NS: I am not massively au fait with philosophy - I only dabble when necessary. If philosophy was my driving passion then I'd be working in a philosophy department. But even I get annoyed by the misuse of the same tired Dewey quotations thrown into EdTech discussions to lend an air of gravitas and TED-talk wisdom. You will be familiar with the sort of things: 'We must prepare our children not for the world of the past, not for our world, but for their world. The world of the future' ... or 'If we teach today as we taught yesterday, we rob our children of tomorrow'. These all look great on an opening slide ...

Now I don't know much about the minutiae of Dewey's thinking, but I'm pretty sure that he wasn't making these points in order to justify the increased use of Microsoft Teams or the whole-school adoption of the Summit Personalised Learning system. So I prefaced the book with one of these quotations to hook in fans of Ken Robinson, Sugata Mitra and Sal Kahn with some comforting familiar-sounding platitudes. Thereafter, my plan was to slowly bring in other aspects of Dewey's thinking as a counterpoint throughout the book, thus undermining the assumption that we need more AI tech in education simply because it is 'the future'. As an aside, I also liked the idea of introducing other readers with a tech background to the idea that is there is a heritage within education of thinking quite deeply about what education is, and what education is for. I was hoping to get tech readers curious to read more of Dewey's original texts, rather than sticking to their own narrow experiences and presumptions of what education is.

PJ: This is an admirable aim, Neil! What kind of schools, and what kind of teaching, do we need for democratic decision-making in present and future? 
NS: I'm glad you raise the issue of decision-making. This is a key way to understand $\mathrm{AI}$ and education at the moment. I think we need to see the major logic of AI (at least for the current generation of AI technologies) in terms of automated decision-making. In other words, these are technologies designed to take data relating to educational settings and make decisions without the involvement of humans. As I argue in Should Robots Replace Teachers?: AI and the Future of Education (Selwyn 2019), these technologies are largely sold as better informing students and teachers - and gently prompting them toward better decisions. This is disempowering enough, but I argue that the logical consequence of having these forms of technology in educational contexts (especially institutions which are already managerially-inflected) is the prospect of humans being directly instructed what to do by the technology. If this is the case, then teachers and students need to be able to recognise what is going on, and respond accordingly. Indeed, these are awarenesses and dispositions that people will need to draw on in all walks of life - from dealing with the Google search results through to gauging when to turn their car over to 'self-driving' mode.

So, as you suggest, this raises the question of what kind of schools and what kind of teaching do we need for democratic forms of this AI-driven decision making (and engagement with AI in general)? My hunch is that there is probably much to be gained by looking back to Dewey in more detail. For sure, there are certainly types of knowledge and understanding that are specific to engaging with AI in this manner. There is something to be said for schools supporting young people to gain a working knowledge of computational logics and fundamentals of data science, as well as some preceding basic understandings of math and statistics. Thereafter, we might do well to think how Dewey's basic pragmatist principles are perhaps lacking from our contemporary models of technology and schooling. Ultimately, my preferred form of schooling in the 'AI age' might involve supporting students to cultivate what Dewey might term good 'habits' around AI - i.e. values and beliefs about what AI should be, and dispositions that guide how one responds to any instance of automated society.

PJ: How do you see this in practice?

NS: In this sense, schools might be recast as places where students are encouraged to engage thoughtfully around AI, and engage in communal inquiry into problems of AI governance, AI ethics and AI development. There are plenty of topics of co-inquiry around automated decision-making that students and teachers might engage in within a school as a way of modelling ways of engage with AI in everyday life. For example, this might be based around processes such as 'white-boxing' the core algorithms that drive their school's main systems and platforms. Students and teachers might co-inquire how their school Learning Management System profiles a student, or how an automated grading (or plagiarism 'detection') system reaches the judgements it does. Student and teachers can then work together to recalibrate these settings in ways that better chime with the common values of the school, or the collective needs of the students. So schools should not be a place where AI is simply 'done' to students. Rather, schools should be places where students learn to interrogate, unpack and reassemble AIdriven technologies, and gain deep knowledge about the parameters of these technologies that will play an ever-expanding influence on their lives. Schools should be places where people learn to live with AI on their own terms. 


\section{Education After Covid-19}

PJ: You are not afraid to try and predict (educational) futures (e.g. Selwyn 2011a, 2011b), and many of your books at least sporadically mention scholars who did similar things before you such as Larry Cuban. Few years ago I interviewed Larry and asked him about his past predictions. Larry admitted that his predictions have not been very accurate and that they wrong predictions always get more attention than correct ones.

For someone who has only a $50 \%$ average in predictions - see forecasts that I made in Teachers and Machines (Cuban, 1986) - I have a mediocre record in looking around the corner (...).

I confess to my errors in foreseeing the future for no other reason than to remind readers, both champions and sceptics of computers in schools, that accurate predictions are rare and inaccurate ones are not only common but often memorable. (Cuban in Jandrić 2017: 12, emphasis original).

Please reflect on your own predictions. What, in your opinion, is their role in development of our understanding of present and future of education?

NS: Ha! It is funny that you see my writing as future-oriented, as I usually think of it in very different terms! One of my ongoing disappointments with a lot of academic EdTech discussions is the relentless description of a world of education that does not yet exist (and one I suspect can never exist). I have always found mainstream EdTech research to be interested primarily in the potential of technology to improve learning and teaching. The prevailing modus operandi is to ask questions of what could be done with technology in classrooms (and by extension, provide a commentary on what should be done). The focus is always on the near future - the next few years and the next big technology. There is little interest in picking over the scrappy realities of how current iterations of educational technology are perhaps not working well for many students and teachers. At best, the response is usually, 'Ah well, this emerging technology will change all that ... once this new thing is being used everything will be better'. This is why those 'Horizon' reports (New Media Consortium n.d.) continue to get so much traction each year. EdTech is always looking slightly ahead of itself, and very reluctant to think about the present ... let alone the past. This is why I describe the field of EdTech as being fixated on the 'state of the art', and far less often interested in the 'state of the actual'.

I should point out at this stage that none of this is meant to be wholly pejorative. In making these observations, I do not consider my own approach to somehow be a superior take on the situation. I can fully understand why mainstream EdTech researchers do the things that they do. I feel sure that most academics who get involved in EdTech usually act with the best of intentions - to help students to learn better, to bring in different forms of pedagogy, or even to widen participation. A lot of people in EdTech see themselves as progressive, liberally-minded and fully concerned with making the world a better place. In this sense, writing and research in the area of education and technology is a 'positive project'. People are always hoping for the best. But this hope can often tip over into a subjective, partisan approach that technology is inherently 'a good thing'. Branding a field of academic inquiry as 'Technology 
Enhanced Learning' is a good example of this. Anyone setting out to research 'Technology Enhanced Learning' has answered their own question before they begin.

This attitude was certainly rife during the 2000 s and the heyday of 'ICT' in UK education. I remember once being asked at a funding interview for a project on school 'learning platforms' with a government agency how we would deal with any 'negative findings'. The chair fixed us in the eye and trotted out a mantra that he obviously used regularly on these occasions - 'Only. Good. News. Will. Be. Used'. Amid the usual guff about objective evaluations and robust studies, this brief moment of honesty shone through. It was useful to know where the 'research' that we were bidding to conduct stood in the grand scheme of things. From then onwards, I have always found that it helps if you treat mainstream EdTech academic literature as a form of propaganda.

PJ: And debunking this propaganda, closely linked to the Californian ideology (Barbrook and Cameron 1996), brings up the importance of political economy. Paraphrasing title of Siân Bayne's (2015) critique of Technology Enhanced Learning, Neil, what is the matter with political economy of EdTech?

NS: The thing that continues to amaze me is how so many people continue to be content to not treat EdTech as a matter of political economy. EdTech is regularly celebrated as a multi-billion dollar (if not trillion dollar) business. The levels of venture capital investment are off-the-scale in comparison to other areas of education. EdTech is clearly entwined with economic systems, class relations, political institutions and everything in-between. Yet, there is a suspicious reluctance amongst most academics who work in the area to make these connections - yet alone act on them. Conversely, people who do spend time exploring this dark side of EdTech run the risk of being sidelined or branded conspiracy theorists. For example, Audrey Watters - a prominent writer and independent scholar - spent the 2010s relentlessly pointing to the worst political economic shenanigans in the area of EdTech, and was regularly shouted down as somehow not 'understanding tech', being 'anti-innovation' or similar. She has recently dialled-back her writing on these issues. There is a curious reluctance to call Google out for their education incursions, or push back against the myriad connections that an organisation such as 'Digital Promise' is founded upon. I do not know whether this is due to a political naivety, or reluctance to bite the hand that feeds. Either way, it makes most critically-minded people quite quickly decide to move on from working in the area of EdTech ... for some reason I have stuck around, and am now firmly stuck here!

PJ: Good to have you around, not the least because we need those with critical voices and those ready to stand up to EdTech propaganda!

NS: Anyway, to get back to 'the future', mostly my approach has been to try remain relentlessly fixated on making sense of the messy realities of the present. However, because this field is so future-focused (especially in terms of policy and industry discourse), I have inevitably found myself getting dragged into talking about the future whether I like it or not. I guess that the main ambition I have for any aspect of my work is to alter the nature of the conversation about education and technology. My research and writing is not going to cure diseases or develop million-dollar patents. But my research and writing can help to develop more diverse and socially-aware discussions, debates and discourses about technology and education, which might help shape how digital education unfolds in more diverse and socially-aware ways. Given these ambitions, then, I increasingly find myself talking about the future simply because so 
many conversations around education and technology are about the future. However, I am under no illusions that I am any better able to 'predict' what is going to happen than anyone else. I am happy to talk about what is possible, and also start conversations about what might be preferable, but I'm careful not to conflate informed speculation with prediction.

In that sense, anything that I've said about the future should definitely not be taken too seriously. I only indulge in talking about the future simply as a means of helping different lines of thought to come through into mainstream discussions of technology and education. For example, living currently in Australia has left me convinced that any talk about digital education needs to rapidly engage with issues of environmental sustainability. This is something that hardly ever gets talked about in terms of EdTech, yet if we take climate science seriously then there is a real possibility that the conditions of digital abundance that EdTech is built around has a very limited shelf-life. The forms of EdTech that we are talking about now are super-precarious. If so, how do we reimagine EdTech for a planet that is not capable of supporting cloud storage, when the idea of reliable connectivity to power (let alone the Internet) is a luxury, when we have to embrace the idea of 'computing within limits'? So, I'm happy to talk about the future of EdTech in order to get these sorts of issues onto the agenda ... but never with any illusions of genuine foresight. At best, any talk about the future is an exercise in thinking more deeply about the present. I would not read anything more into it than that!

PJ: With all this in mind, please try and predict the future of education after the Covid-19 pandemic. Which main problems, and which main areas of education, should we keep an eye on in the times that come?

NS: So, mindful of everything I have just said, I can attempt some informed speculation about the next 5 years or so ... hopefully a period where we will have learnt how to live with this virus. For me, the biggest trap for any critical forwardlooking account of education and technology is to lapse into is the slightly worldweary, cynical response that we are only going to see more of the same ... 'same shit, different bucket' as people are fond of saying in Australia. That said, we are certainly seeing Covid-19 prompting the resurgence of a lot of dominant tech-fuelled 'corporate education reform' logics from the past 20 years or so. Rolin Moe recently tweeted that the education 'disrupters' are back again, but this time their talk of 'innovation' is rebranded as 'revolution'. In many ways, the pandemic has given the usual suspects from within the world of education reform a fresh impetus to push their agendas onto school and university systems around the world.

So, one response to your question is that perhaps a lot of what we are likely to see over the next 5 years might be best described as an acceleration of pre-existing logics. For example, the post-pandemic push for universities to 'pivot' to online provision, prioritise short industry-facing courses, and close down humanities and arts departments is not surprising - especially set amid the wider context of a world that for the foreseeable future will be physically-distanced and dealing with a global financial crisis. Similarly, schools have been pushed for the past decade in the direction of personalised learning systems, adaptive curricula, data-driven instruction, blended learning and the like. So, we can easily foresee a future where these logics now quickly become established into mainstream education reform under the guise of establishing a 'new normal'. 
PJ: These days, a 'new normal' has become a catchphrase that can mean almost anything... How can we try and unpack it?

NS: Amid this turmoil it is always most interesting to ask two questions: 'What is new here?' and 'How might things be otherwise?'. In terms of what might be new here, a number of possibilities come to mind - especially if we try to 'follow the money' and look at how commercial priorities are shifting. For example, there is already an influx of new faces coming into EdTech investment. If nothing else, the transformation of Zoom into a staple school platform has revived hopes that there are big profits to be made in the education technology space. As observers like Ben Williamson are beginning to note on Twitter, the market is also taking note of the rise in so-called 'direct-to-consumer' EdTech products - from Khan Academy to BrainPOP. So, expect to see the rise of direct-to-student platforms and services over the next few years, especially as middle-class parents are now more engaged consumers with first-hand experience of how all this stuff works (and does not work).

Investors are already talking about the profitability of 'family-friendly' EdTech, so a likely market trend over the next few years will be targeting parents - instead of teachers and schools - as the primary market for digital education (see Koenig 2020; TechCrunch 2020). This shift in emphasis will make particular commercial sense as the budgets for schools are cut during the economic crisis. How this alters the forms of technology that get pitched to schools will be interesting. Another example of this decentring of the school may well be a boom in online tutoring services. The lockdown showed a spike in richer families employing online virtual tutors - either to provide supplementary tuition, or to simply oversee their child's remote schooling. If we follow the logic of digital labour, these services will be increasingly outsourced to remote armies of low-paid online para-pedagogical support. None of this will result in the absolute 'death of school' ... but might cumulatively contribute to the further erosion of the idea of public education.

PJ: I agree with you about the possibility of erosion (of the idea) of public education, and I am horrified by it! Yet I refuse to succumb to negative thoughts, and insist that we need to seek opportunities for change for the better. In March 2020 I issued a Call for Papers for this issue of Postdigital Science and Education titled 'The Day after Covid-19'. With this title, I wanted to emphasize the importance of looking forward - the Covid-19 pandemic is a huge disruption to our way of life, yet it is also an opportunity to challenge and hopefully improve the existing order of things. It could be that the Covid19 pandemic could also provide an opportunity to develop a better and more just 'new normal'. Which opportunities within the pandemic can you identify for improving education for the post-pandemic world?

NS: Yes! That brings me to the second of my two previous questions. In terms of thinking how might things be otherwise, a number of alternate possibilities are definitely apparent. This is where the idea of thinking about 'futures' (plural) is important as way of unsettling what we see as possible. For example, we might see the mainstream uptake of grass-roots, community-driven online education. As we write this article, some people are getting excited about the apparent rise in 'home made' peer-to-peer educational content on TikTok. As someone who remembers the hype surrounding MySpace, Club Penguin, Facebook and similar 'free' spaces for usergenerated education I remain sceptical. We should not forget that TikTok is a product 
of a large corporation which was already trying to monetise what it then pitched as '\#EduTok' content well before the pandemic.

Instead, it might be more exciting to run with the logics inherent in nascent ideas such as the establishment of a nationwide virtual 'Open School' in England - along similar lines the UK's Open University. Over here in Australia, people have been vaguely talking about revisiting the heritage of the radio-based 'School Of The Air'. As I mentioned earlier, the Covid-19 lockdowns have foregrounded the stark inequalities in people's capacities to engage with current forms of digital education. It would be nice to imagine that the pandemic might prompt a radical shift toward more communal, collective forms of digital engagement ... digital learning that is reimagined along collectively-organised - rather than self-regulated - lines.

\section{References}

Anderson, M., \& Perrin, A. (2018). Nearly one-in-five teens can't always finish their homework because of the digital divide. Washington, DC: Pew Research Centre, 28 October. https://www.pewresearch.org/facttank/2018/10/26/nearly-one-in-five-teens-cant-always-finish-their-homework-because-of-the-digitaldivide/. Accessed 30 June 2020.

Barbrook, R., \& Cameron, A. (1996). The Californian ideology. Science as Culture, 6(1), 44-72.

Bayne, S. (2015). What's the matter with 'technology-enhanced learning'? Learning, Media and Technology, 40(1), 5-20. https://doi.org/10.1080/17439884.2014.915851.

BBC News (2020). Coronavirus: Home-schooling six children with just one phone. 19 May. https://www.bbc. com/news/av/education-52717519/coronavirus-homeschooling-six-children-with-just-one-phone. Accessed 29 June 2020.

Bhatia, R. (2016). The inside story of Facebook's biggest setback. The Guardian, 12 May. https://www. theguardian.com/technology/2016/may/12/facebook-free-basics-india-zuckerberg. Accessed 29 June 2020.

Feenberg, A. (2019). Postdigital or predigital? Postdigital Science and Education, 1(1), 8-9. https://doi. org/10.1007/s42438-018-0027-2.

Gates, B. (1996). Content is king. 3 January. https://web.archive.org/web/20010126005200/http://www. microsoft.com/billgates/columns/1996essay/essay960103.asp. Accessed 29 June 2020.

Hayes, S., Jopling, M., Hayes, D., Westwood, A., Tuckett, A., \& Barnett, R. (2020). Raising regional academic voices (alongside data) in higher education (HE) debate. Postdigital Science and Education. https://doi.org/10.1007/s42438-020-00131-6.

Jandrić, P. (2016). The methodological challenge of networked learning: (post)disciplinarity and critical emancipation. In T. Ryberg, C. Sinclair, S. Bayne, \& M. de Laat (Eds.), Research, boundaries, and policy in networked learning (pp. 165-181). New York: Springer. https://doi.org/10.1007/978-3-31931130-2_10.

Jandrić, P. (2017). Learning in the age of digital reason. Rotterdam: Sense.

Jandrić, P. (2019). Welcome to Postdigital science and education! Postdigital Science and Education, 1(1), 13. https://doi.org/10.1007/s42438-018-0013-8.

Jandrić, P., Knox, J., Besley, T., Ryberg, T., Suoranta, J., \& Hayes, S. (2018). Postdigital science and education. Educational Philosophy and Theory, 50(10), 893-899. https://doi.org/10.1080 /00131857.2018.1454000.

Jandrić, P., \& Kuzmanić, A. (2020). Uncanny. Postdigital Science and Education, 2(2), 239-244. https://doi. org/10.1007/s42438-020-00108-5.

Knox, J. (2019). Postdigital as (re)turn to the political. Postdigital Science and Education, 1(2), $280-282$. https://doi.org/10.1007/s42438-019-00058-7.

Koenig, R. (2020). The post-pandemic outlook for EdTech. EdSurge, 11 June. https://www.edsurge. com/news/2020-06-11-the-post-pandemic-outlook-for-edtech. Accessed 30 June 2020.

Lacković, N. (2020). Postdigital living and algorithms of desire. Postdigital Science and Education. https://doi.org/10.1007/s42438-020-00141-4.

Levinson, P. (2019). Needed: A 'Post-Post' formulation. Postdigital Science and Education, 1(1), $14-16$. https://doi.org/10.1007/s42438-019-0031-1. 
Miks, J., \& McIlwaine, J. (2020). Keeping the world's children learning through COVID-19. UNICEF, 20 April. https:/www.unicef.org/coronavirus/keeping-worlds-children-learning-through-covid-19. Accessed 30 June 2020.

New Media Consortium (n.d.). Horizon reports. https://1ibrary.educause. edu/search\#?publicationandcollection_search=Horizon\%20Report. Accessed 29 June 2020.

Samsung (2013). Samsung harnesses solar power to build Samsung digital villages in Africa. 23 October. http://bit.ly/1QU0j6S. Accessed 29 June 2020.

Sawchuk, S., \& Samuels, C. (2020). Where are they? Students go missing in shift to remote classes. Education Week, 10 April. https://www.edweek.org/ew/articles/2020/04/10/where-are-they-students-go-missing-in. html. Accessed 30 June 2020.

Selwyn, N. (2011a). Education and technology: Key issues and debates. London and New York: Continuum.

Selwyn, N. (2011b). Schools and schooling in the digital age: A critical analysis. New York and London: Routledge.

Selwyn, N. (2013). Education in a digital world: Global perspectives on technology and education. New York and London: Routledge.

Selwyn, N. (2019). Should robots replace teachers?: AI and the future of education. Cambridge, UK: Polity.

Selwyn, N. (2020). Meet the education researcher. Post-digital education (Siân Bayne). https://soundcloud. com/eetheducationesearcher/post-digital-education-sian-bayne. Accessed 29 June 2020.

Selwyn, N. (2021). Education and technology: key issues and debates. Third edition. London: Bloomsbury.

Selwyn, N., \& Brown, P. (2000). Education, nation states and the globalization of information networks. Journal of Educational Policy, 15(6), 661-682. https://doi.org/10.1080/02680930010000245.

Sinclair, C., \& Hayes, S. (2019). Between the post and the com-post: Examining the postdigital 'Work' of a prefix. Postdigital Science and Education, 1(1), 119-131. https://doi.org/10.1007/s42438-018-0017-4.

Taffel, S. (2016). Perspectives on the postdigital: Beyond rhetorics of progress and novelty. Convergence: The International Journal of Research into New Media Technologies, 22(3), 324-338. https://doi.org/10.1177 /1354856514567827.

TechCrunch (2020). EdTech is surging and parents have some notes. TechCrunch, 10 June. https://techcrunch. com/2020/06/09/edtech-is-surging-and-parents-have-some-notes/. Accessed 30 June 2020.

Wikipedia (2020). Sayre's law. https://en.wikipedia.org/wiki/Sayre\%27s_law. Accessed 29 June 2020. 